\title{
RELIGIOSIDADE E IMAGINÁRIO NO BRASIL DO SÉCULO XIX
}

DOI: http//dx.doi.org/10.15448/2178-3748.2017.1.25341

\author{
Eduardo Melin \\ Mestrando em Historia UNESP \\ eduardo.melin@hotmail.com
}

DEL PRIORE, Mary. Do Outro Lado. História do Sobrenatural e do Espiritismo. São Paulo: Planeta, 2014.

Depositário de filosofias e ciências europeias, mas singular no processamento destas, o imaginário do Brasil no século XIX é abarrotado de contribuições intelectuais, sobretudo francesas, que o tornaram um crente devoto, porém relapso, das ideias do progresso. Nesse ínterim, a religiosidade se manifesta num sincretismo de práticas e adorações, sendo o contato com o sobrenatural a marca que maior caracteriza a mentalidade comum a diversas camadas sociais brasileiras. É nesse sentido oculto que a obra "Do outro lado", de Mary del Priore, transmite da maneira mais clarividente possível, os costumes e as esparsas formas de religiosidade durante o século XIX.

Autora reconhecida por suas pesquisas acerca do universo cultural brasileiro e suas mentalidades, vem cativando uma vasta gama de leitores por seus fascinantes temas e sua volumosa produção bibliográfica. Graduada em História pela Pontifícia Universidade Católica de São Paulo (1983), concluiu seu Doutorado em História Social pela Universidade de São Paulo e defendeu sua tese de Pós-Doutorado pela École des Hautes Études en Sciences Sociales, em Paris (1996). Premiada diversas vezes pela Fundação Joaquim Nabuco e pelo solene prêmio literário Jabuti, entre 1998 e 2000, por mérito de seus livros História das Mulheres no Brasil e História das Crianças no Brasil, desenvolveu pesquisas que vão da história colonial, história de gênero a amplas áreas da cultura, vida social no século XIX, tendo maior destaque biográfico de expoentes do período imperial brasileiro, como $\mathrm{O}$ príncipe maldito (2007), A Carne e o Sangue. A Imperatriz D. Leopoldina, D. Pedro e Domitila, a Marquesa de Santos (2012), Condessa de Barral, a paixão do Imperador e O Castelo de Papel (2013). Atualmente é professora do Programa de Mestrado em História da Universidade 
Salgado de Oliveira - UNIVERSO/NITERÓI e contribui como correspondente de diversas academias e institutos de pesquisa na América Latina.

Tais publicações indicam que o livro é fruto de pesquisas que a historiadora vem desenvolvendo em cultura, mentalidade e vida social no Rio de Janeiro do século XIX, visto que o cenário da religiosidade é a base que estatui o complexo raciocínio presente na obra. Por meio de questionamentos sobre a existência para além da morte, a autora introduz o tema fazendo menção às experiências do passado com o desconhecido, ressaltando a importância que os mortos exerciam sobre os vivos. Por meio dessa alusão, ela recupera a ligação dimensional entre o presente e o futuro, como um fenômeno que provoca anseios e incertezas desencadeando uma busca incessante pelo amanhã que, por meios esotéricos procuraram satisfazer a debilidade de suas certezas com cartomantes, videntes, quiromancia, entre outros meios ocultos que pudessem garantir a segurança de inquietações pelo porvir.

Como instrumento para o trabalho, a autora se reporta às em fontes midiáticas do século XIX, jornais, revistas, crônicas relatos e análises de autores que tratam de temas semelhantes - como Gilberto Freire no que condiz a cultura religiosa de cunho africano -, sempre mantendo uma relação interligada a manifestações intelectuais no exterior que poderiam levantar hipóteses sobre a causa das projeções histórico-culturais no Brasil oitocentista.

No primeiro capítulo, "Como tudo começou", Del Priore relaciona um cenário de desencantamento provocado pelo avanço das ciências e do racionalismo que apontava as fragilidades da doutrina cristã, buscando explicação para o que até então era dado como mistério. Ao mesmo tempo em que as pessoas recorriam ao sobrenatural por meio de diversas doutrinas, em busca das crenças de que precisavam para aliviar as vicissitudes do cotidiano.

O racionalismo e a precisão do século XIX não tiraram a ansiedade dos indivíduos na busca por respostas do amanhã ou do post mortem. A razão não apagou a crença no além, em uma época marcada pela melancolia, pelo sobrenatural contido nas obras de Byron e Victor Hugo e a presença dos mortos e criaturas das sombras em contato com os vivos.

Na terceira parte desse capítulo inicial, Del Priore conta histórias das esferas espirituais do "Outro Mundo", desde o Sheol judaico ao inferno e paraíso do século II, mencionando a presença no Antigo Testamento de proibições do contato com os mortos - orientação que evolui com a chegada de Cristo e as ressurreições de indivíduos descritas nos evangelhos -, para uma época em que a criação do purgatório no século XIII traz certa esperança aos fiéis falecidos que buscavam a purificação com ajuda das orações do mundo dos vivos. O ambiente soturno da morte atraía desde intelectuais e estudantes a fiéis, senhoras encantadas com o vislumbre e o prazer dos enterros e cemitérios. 
No segundo capítulo, "A nova moda: As mesas volantes e o Espiritismo", a autora introduz as primeiras manifestações de fenômenos paranormais através dos episódios ocorridos nos Estados Unidos, em que as irmãs Kate e Maggie Fox se comunicavam com alguma entidade por meio de batidas nas paredes. $\mathrm{O}$ fato teve tamanha repercussão que tomou salões com apresentações do caso das irmãs, estas atraíram investigações frequentes com a finalidade de examiná-las procurando alguma fraude em tal fenômeno. Mesas volantes, prática também espiritualista que se difundiu na metade do século XIX, também são tema para discussão sobre os primórdios dos eventos sobrenaturais do período, assunto que Del Priore busca na história antiga equivalentes de aproximadamente 200 d.C., afirmando que o contato sempre existiu antes mesmo da doutrina.

No subcapítulo que trata da existência ou não do sobrenatural, a autora traz a história do Brasil oitocentista permeado de prosperidade e remonta as ambições modernizadoras para o país, mas ao mesmo tempo expõe a realidade condizente com as condições físicas e estruturais da capital Rio de Janeiro, que não se encaixam em nenhum padrão de proposta progressista. Ainda nessa parte, são discutidas as situações de sincretismo religioso nas quais a ambiguidade quanto à confiança no catolicismo dá brechas para a busca por uma mistura na religiosidade que envolve práticas africanas e espiritualistas.

Outro subcapítulo da obra discorre sobre "revelações", retomando a formação e introdução de Allan Kardec como fundador da doutrina espiritualista, baseada no próprio pseudônimo por ele adotado, de origem celta, povo que mantinha a crença cíclica espiritual, segundo a qual a morte era apenas uma passagem para outra existência. É Interessante ressaltar sobre a ideologia de reencarnação, que a autora associa à ideia de desenvolvimento e progresso - visto que dentro da ótica espírita, o repúdio às revoluções de objetivo igualitário era claro, pois acreditavam que a ordem hierárquica do mundo se encaixa na ideia de aprendizado humano para expiação de suas mazelas, problemas que se resolveriam não pela revolução do proletariado, mas pela caridade típica da utopia socialista de Owen.

Para Del Priore, a recepção do espiritismo no Brasil, um país oficialmente católico, passou por certa intolerância. As obras de Kardec eram vistas como um ultraje aos conceitos pétreos da doutrina Cristã, já que desmistificavam a existência de inferno, anjos e demônios, e ao declarar a existência da reencarnação, negavam a visão escatológica da Igreja sobre o juízo final. Dessa forma, além de serem estigmatizados no jornal O Apóstolo, muitos livros conheceram a fogueira da Inquisição e seus títulos foram listados no Index do Tribunal do Santo Ofício. 
Essa relação hostil com a Igreja Católica era uma reação não só às obras de Kardec, mas também às notícias dos jornais da época, como Jornal do Comércio, Jornal Courrier, a Editora Garnier e o Diário de Pernambuco que enfatizavam os acontecimentos com as mesas volantes pela Europa e evidenciavam que tais práticas estavam ocorrendono Brasil. Contudo, mesmo que o censo demonstre que havia cem por cento de católicos, estes só se declaravam como tais por necessidade, haja vista que só colava grau acadêmico e participava de eleições quem fosse católico. Na prática, predominava o sincretismo que aglutinava o credo católico com a doutrina espírita e ou africana.

O espiritismo no Brasil atingia diversas camadas sociais e se difundiu muito bem na Bahia, região na qual surge o primeiro jornal "O Eco do Além Túmulo" e o primeiro Grupo Familiar do Espiritismo, em 1865. Entretanto, mesmo com a tentativa de autorizar o funcionamento da Sociedade Espirita Brasileira, a Igreja levanta novos obstáculos que seriam atenuados com a Questão Religiosaque opôs católicos e maçons de 1872 eque a desvencilha do Estado, fato que abre espaço para a difusão do espiritismo na Corte Imperial.

No terceiro capítulo, “Outras Manifestações do Além, Curandeiros, Cartomantes e Exorcistas", Del Priore narra o problema referente à falta de compromisso assumida pelo Estado diante da saúde pública, fato que evidencia a escassez de médicos. A partir de 1880, a frequência de denúncias em jornais se tornou cada vez maior, nestas os médiuns eram tratados como curandeiros, feiticeiros e charlatães.

Em seguida, a autora discute a origem das Cartomantes no Brasil, muito comparadas aos espíritas por seu aspecto místico e clarividente. A princípio, Del Priore introduz a vaga possibilidade de que as leitoras do futuro tivessem sido introduzidas no cotidiano brasileiro por meio de ciganos, logo é salientado a possível hipótese de sua proveniência francesa, visto que personalidades do pós-revolução por muito consultaram seus destinos com tais métodos. Preenchiam as ruas das cidades e as páginas de jornais, nos quais eram criticadas. Contudo, mais repreendidas ainda eram as pessoas que as consultavam, vistas como gente fraca de espírito e desequilibradas. O fato é que acertando ou não o destino, tais videntes solucionavam dúvidas que nenhum outro poderia fazer, saciavam a sede pelo desconhecido e acalmavam temores pelo futuro.

Ao lado do paredão de ilusões desse mundo enigmático, encontra-se o exorcista. Nesse subcapítulo são apontados casos de pessoas que sofreram possessões demoníacas, consideradas pelos espíritas como histéricas, mas que eram até mesmo tratadas por padres católicos. A histeria por muito tempo foi vista como obra do demônio, muito associada à mulher devido a sua herança pecaminosa herdada de Eva, que segundo as sagradas escritura 
manteve diálogos com a serpente. Devido a casos como esses eram aplicadas práticas exorcistas por meio do livro rituale, que ocorriam em lugares nas cidades que funcionavam de manhã à noite.

O mesmo subcapítulo trata também do sonambulismo e explica que a cura para tais histerias, dores e desequilíbrios, muitas vezes se encontrava na prática da hipnose, embora fosse vista como misteriosa, foi um dos poucos métodos utilizados por médicos, como por um dos fundadores da neurologia, Dr. Charcot, que ao invés dos tratamentos bizarros para loucura, como choques elétricos, banhos de água gelada e introdução de agulhas e anestésicos, buscava no sonambulismo da hipnose um meio para resolver as mazelas humanas pela indução do pensamento.

No seguinte capítulo, "Os Inimigos do Além”, a autora enumera casos em que o sentimento de repúdio para com o espiritismo é frequente. As hostilidades partiam da imprensa, dos médicos, da igreja católica que condenava as reuniões e práticas como magia vinda do inferno. Tamanha era a antipatia desses grupos conservadores, que mesmo na Europa onde era mais difundida e até entendida como filosofia, nas primeiras tiragens da enciclopédia Larousse, a palavra espiritismo era associada à doença mental e o nome de Allan Kardec agregado ao significado de perturbador e causador de doenças psíquicas. Até mesmo Machado de Assis que partilhou do meio de intelectuais e pessoas influentes que frequentavam grupos espíritas, alfineta o espiritismo com ironia e desprezo em seus contos e obras.

$\mathrm{Na}$ segunda parte do quarto capítulo, Del Priore discorre sobre os conflitos entre o espiritismo, que se portava passivo na maior parte das vezes, e a hostilidade dos médicos que procuravam acabar com a doutrina, tratando-a como comprometedora da sanidade mental. Muitos ataques a curandeiros e hipnotizadores eram feitos nesse período, mas não tanto quanto ao espiritismo, pois consideravam que o espírita era ignorante na arte da cura, sendo o médico, estudado e formado nas ciências, o único capaz de tratar enfermidades e trazer segurança e benefício ao paciente. Entretanto, o problema da escassez e o alto custo das consultas dos doutores da medicina ocasionavam uma menor procura. Desse fato é que, segundo a autora, parte o ataque desenfreado à cura e tratamento realizados nos centros espíritas do início do século XX. A limpeza urbana desse início de século deu brecha para a limpeza mental proposta por esses médicos, que queriam extirpar o espiritismo do meio social para purgar a sociedade dessas práticas por eles denunciadas como prejudiciais à saúde dos indivíduos.

Engajadas ao conteúdo enigmático como baixo espiritismo, as "casas de preto", lugares em que as variações religiosas africanas tinham vez, onde danças e rituais eram realizados com a participação de diversas camadas sociais, entre as quais incluíam-se líderes de terreiro, que 
mesmo pretos, no crepúsculo da escravidão tinham muita influência entre grandes magnatas da época, exerceram importante papel cultural nesse período. Esse é o caso de Juca Rosa, "senhor de forças sobrenaturais", líder de seita africana, que partilhava de uma mistura com o catolicismo e curas em geral, seus rituais, repercussão e fanatismo mostravam o prestígio que ganhara na década de 70 , contudo a promiscuidade com que tratava suas fiéis acabara por levá-lo a prisão em 1871.

A autora encerra o capítulo na aurora da República, com a proibição no Código Penal de 1890 da prática do espiritismo pelos republicanos positivistas. Essa atitude se explica pela vinculação destes com o empirismo. Certa ditadura da ciência e da razão permeava o final do século XIX e condenava como atrasado tudo aquilo que não fosse provado cientificamente, até mesmo como anteriormente foi tratado de crime de saúde pública, o espiritismo era associado às religiões africanas pela crença e cura pelos espíritos, o que não agradava, nem adornava a face da nova República que acabara de abolir a prática escravista e que queria abandonar de uma vez por todas esse passado "negro" da história do Brasil.

No último capítulo, "O Eterno Sobrenatural", Del Priore entra no século XX ao mencionar aspectos ideológicos da Belle Époque, em que apesar das ciências e da razão se destacarem com o apogeu faustoso da civilização, o temor quanto a esse progresso conduz a mentalidade popular a se refugiar nas veredas misteriosas da crença.

Entretanto, há também certo movimento que se enquadra à nova República que tentava de formas adversas se encaixar nos moldes europeus, mas sofria com os dissabores econômicos e sociais das primeiras experiências capitalistas. A ideia de progresso moral atravessa a mente de pessoas e grupos espíritas, positivistas, weberianos que veem como hostilidade em comum o atraso e o repúdio ao catolicismo. Embora, como o cronista João do Rio não deixa generalizar, muitos casos de dissidentes do espiritismo usavam nomes de santos católicos em suas casas. O espiritismo se espalhou por toda a recém-proclamada República, mesmo com as proibições no Código Penal. O decorrer do século atenuou as proibições e diversos grupos buscavam no mistério algo que solucionasse suas inquietações.

Observa-se no decorrer da obra que a autora incita o leitor com análises de fatos que passam despercebidos da história brasileira no período imperial. A escolha por fontes do cotidiano aproxima o leitor de um ambiente popular e cultural que lhe é conhecido e o insere dentro dos grandes acontecimentos da época além de minuciosos momentos em que a mentalidade e a concepção de valores são autoras de eventos que dialogam de forma clara com o cotidiano presente dos leitores. A autora encerra o livro com o desabrochar do século XX, relacionando a ideologia do progresso com a concepção de algumas nuances do espiritismo 
que trabalha com a evolução espiritual. Compreende por fim, que mesmo com as novas formas de encarar a realidade, encontrando na ciência uma religião de ortodoxia inquestionável, a crença ainda sobrevive. 